\title{
Is the proportion of per capita fat supply associated with the prevalence of overweight and obesity? an ecological analysis
}

\author{
Hasinthi Swarnamali ${ }^{1}$, Ranil Jayawardena ${ }^{2,3}$, Michail Chourdakis ${ }^{4}$ and Priyanga Ranasinghe ${ }^{5^{*}}$ (D)
}

\begin{abstract}
Background: Although it is reported in numerous interventional and observational studies, that a low-fat diet is an effective method to combat overweight and obesity, the relationship at the global population level is not well established. This study aimed to quantify the associations between worldwide per capita fat supply and prevalence of overweight and obesity and further classify this association based on per capita Gross National Income (GNI).

Methods: A total of 93 countries from four GNI groups were selected. Country-specific overweight and obesity prevalence data were retrieved from the most recent WHO Global Health Observatory database. Per capita supply of fat and calories were obtained from the United Nations Food and Agricultural Organization database; FAOSTAT, Food Balance Sheet for years 2014-2016. The categorizations of countries were done based on GNI based classification by the World Bank
\end{abstract}

Results: Among the selected countries, the overweight prevalence ranged from 3.9\% (India) to 78.8\% (Kiribati), while obesity prevalence ranged from 3.6\% (Bangladesh) to 46.0\% (Kiribati). The highest and the lowest per capita fat supply from total calorie supply were documented in Australia (41.2\%) and Madagascar (10.5\%) respectively. A significant strong positive correlation was observed between the prevalence of overweight $(r=0.64, p<0.001)$ and obesity $(r=0.59, p<0.001)$ with per capita fat supply. The lower ends of both trend lines were densely populated by the lowand lower-middle-income countries and the upper ends of both lines were greatly populated by the high-income countries.

Conclusions: Per capita fat supply per country is significantly associated with both prevalence of overweight and obesity.

Keywords: Ecological analysis, Fat supply, Obesity prevalence, Overweight prevalence

\section{Background}

The global prevalence of overweight and obesity has increased in both children and adults during the past 20 years [1]. Overweight and Obesity are the medical conditions in which excess body fat has accumulated to an extent that it may have important public health

\footnotetext{
*Correspondence: priyanga.ranasinghe@gmail.com

${ }^{5}$ Department of Pharmacology, Faculty of Medicine, University

of Colombo, Colombo, Sri Lanka
}

Full list of author information is available at the end of the article problems associated with an increased risk of type-2 diabetes mellitus, dyslipidemia, hypertension, and cardiovascular disease (CVD) [2]. The World Health Organization (WHO) describes overweight and obesity as among the most visible, yet neglected public health problems [3]. They threaten public health in both developed and developing countries. Parameters that contribute to variations in the development and consequences of overweight and obesity have been related to multiple risk factors, but the recent epidemic is mainly due to the changes 
in lifestyle, namely the lack of physical activity and changes in dietary habits $[4,5]$. Chronic overfeeding is one of the fundamental risk factors that have been identified, as it accumulates energy stores and leading to the development of overweight and obesity [6]. Therefore, a common approach to combat overweight and obesity has been to limit the energy intake.

Sources of energy are macronutrients and alcohol and most foods and beverages contain combinations of carbohydrates, proteins, and fats macronutrients in varying amounts. Dietary fat intake often has been claimed as responsible for the increase in adiposity [7, 8]. However, total energy balance is what matters most and the focus on dietary fat consumption must be seen through its effects on total energy intake (TEI). A significant positive relationship has been found between the amount of energy from fat and the proportion of the population who are overweight in epidemiological studies $[9,10]$, and in clinical studies between the level of dietary fat and body-weight gain as well as between the reduction in the dietary fat and weight loss [11, 12].

People from different countries have distinctive food consumption patterns due to variations in availability, affordability, and local dietary habits [13]. At the same time, food production modernization and rising income levels in the last decades have made a range of foods easily available and affordable with less seasonal variation in some countries $[14,15]$. Although it is widely reported that a low-fat diet is an effective method of weight loss [16-18], its relationship with overweight and obesity trend at the global population level is not well established. Meanwhile, global patterns, distributions, and heterogeneity of consumption of dietary fat have been exhibited [19]. Therefore, it is useful to look at this relationship with nationally representative data. This study explored the associations of per capita fat supply with the worldwide prevalence of overweight and obesity. Furthermore, we aimed to quantify this relationship further based on per capita Gross National Income (GNI) classifications by the World Bank.

\section{Methods}

The correlation between the prevalence of overweight/ obesity in the population and per capita fat supply was investigated using income stratification. For this ecological study, country-specific data were obtained. The countries were selected based on the availability of data for all relevant variables chosen for the study.

\section{Data sources}

The WHO Global Health Observatory (WHO-GHO) database was used to acquire the prevalence rates for overweight and obesity in adults for the year 2016 (the most recent dataset version) [20]. Per capita fat and calorie supply were collected from the United Nations (UN) Food and Agricultural Organization database; FAOSTAT Food Balance Sheet (FAOSTAT-FBS) data for years 2014-16 which was backdated to reflect exposure with delayed presentation [21]. The categorization of countries was done based on the world's economies classified by the World Bank [22]. FAOSTAT-FBS data by country from 2014-16 with WHO-GHO data in 2016 under four income groups are presented in Supplementary Table 1.

\section{The WHO-GHO data}

The WHO-GHO is a WHO project to disseminate global health data, including statistics by country and information on particular diseases and health interventions [20]. The WHO-GHO collects prevalence data on biological risk factors, such as mean BMI, overweight, and obesity, for WHO member countries using defined methodologies [20]. For the most current and updated datasets version, WHO-GHO statistics on estimated prevalence rates of overweight and obesity (percent of the population aged 18 + with BMI 25 and $30 \mathrm{~kg} / \mathrm{m}^{2}$ respectively) per country were gathered (2016) [20].

\section{The FAOSTAT-FBS data}

The FAOSTAT database disseminates statistical data collected and maintained by the FAO. FAOSTAT data are provided as a time-series in most domains through a FBS [21]. The FBS provides a complete view of a country's food supply structure over a defined time frame. The FAOSTAT-FBS gives yearly statistics per country on the daily supply of total calories (in kcal per day), protein (in gram per day), and fat (in gram per day). The FAOSTAT FBS data were used to derive the daily caloric supply and macronutrients of fats (animal and plant, in gram/capita/ day) [21] by the country for the period between 2014-16.

The number of calories from fat was determined using the Atwater energy density method [23]. The mean values for calories and fat per person per day were calculated over a three-year period (2014-16) to represent typical dietary fat exposure, because obesity begins to develop after repeated exposure to dietary risks, and the mean of three years of fat may also reduce random errors during FAO data gathering and computation. The reasoning for this approach is because it has previously been demonstrated that one to three years is a reasonable time frame for estimating a country's obesity prevalence after exposure to dietary risk [24]. The percentage of calories obtained from fat might therefore be computed by 
dividing the total daily caloric supply by the amount of calories derived from fat.

\section{The World Bank data}

The World Bank defines the world's economies into four income categories: "high", "upper-middle", "lower-middle", and "low". Official World Bank estimates of the scale of economies are based on per capita GDP translated to current US dollars (\$) using the World Bank Atlas technique [25]. These four classifications of countries are determined by a country's GNI per capita, which can change with economic growth, inflation, exchange rates, and population [26]. For the current financial year 2020, low-income economies are defined as having a GNP per capita of $\$ 1,035$ or less in 2019; lower-middle-income economies have a GNP per capita between $\$ 1,036$ and $\$ 4,045$; upper-middle-income economies have a GNP per capita between $\$ 4,046$ and $\$ 12,535$; and high-income economies have a GNP per capita of $\$ 12,536$ or more [22].

\section{Data extraction and analysis}

All data were extracted and recorded in Microsoft Excel ${ }^{\circledR}$ [version 2013 for Windows] for analysis by one reviewer (HS) using a standardized form, and correctness was confirmed by a second reviewer (PR). Disagreements in the retrieved data were addressed by discussion, with the assistance of a third reviewer where necessary (RJ). The prevalence estimates of overweight and obesity were matched to the year- and country-specific fat intake variable using data from 93 countries. The World Bank dataset was used to classify an income stratum based on GNP. A correlation coefficient was used to investigate the association between per capita fat supply and other dependent variables such as the prevalence of overweight and obesity. The World Bank income categorization was used to categorize countries for correlation analysis. Pearson's correlation coefficients $(r)$ were computed to assess the strength and direction of the correlations between per capita fat supply and overweight and obesity prevalence. Scatter plots were used to visualize the correlation, and the outcome was examined by constructing a regression line. All countries were named by a three-letter country code in line with International Organization for Standardization 3166, which was taken from the United Nations Statistics Divisions' Terminology Bulletin Country Names and Country Codes for Statistical Use [27].

\section{Results}

Data were analysed for a total of 93 countries among the 4 income groups (low-income $=23$; lower-middle-income $=26$; upper-middle-income $=23$; highincome $=21$ ). With regards to overweight and obesity prevalence data, Kiribati showed the highest overweight and obesity prevalence ( $78.8 \%$ and $46.0 \%$ respectively), while India showed the lowest overweight prevalence (3.9\%) and Bangladesh showed the lowest prevalence for obesity (3.6\%). For the period 2014-16 years, the per capita percentage of fat supply ranged from $10.5-41.2 \%$ of total caloric supply, whereas the lowest and highest percentages of per capita fat supply were reported for Madagascar and Australia, respectively.

Table 1 summarizes the correlations based on economic status as defined by the GNI for the included 93 countries. A strong positive Pearson's correlation coefficient was observed between both the prevalence of overweight $(r=0.64, p<0.001)$ and obesity $(r=0.59$, $p<0.001)$ with per capita fat supply. When countries were categorized based on income; significant positive correlations were exhibited for both overweight and obesity prevalence $(r=0.42, p=0.03$ for both) in the lower-middle-income countries. And, a significant positive correlation was observed only for overweight prevalence $(r=0.53, p=0.01)$ in the high-income countries. However, there was no significant association in

Table 1 Correlation coefficient and coefficient of determination between per capita fat supply and dependent variables of overweight and obesity based on the economic strata classification

\begin{tabular}{|c|c|c|c|c|c|c|}
\hline \multirow[t]{2}{*}{ Correlation } & \multicolumn{3}{|c|}{ Overweight } & \multicolumn{3}{|c|}{ Obesity } \\
\hline & $r$ & $p$ & $\mathrm{R}^{2}$ & $r$ & $p$ & $\mathrm{R}^{2}$ \\
\hline All countries & 0.64 & $<0.001$ & 0.41 & 0.59 & $<0.001$ & 0.34 \\
\hline \multicolumn{7}{|l|}{ Income status } \\
\hline Low & 0.23 & 0.28 & 0.05 & 0.29 & 0.17 & 0.09 \\
\hline Lower middle & 0.42 & 0.03 & 0.17 & 0.42 & 0.03 & 0.18 \\
\hline Upper middle & 0.24 & 0.27 & 0.06 & 0.28 & 0.08 & 0.08 \\
\hline High & 0.53 & 0.01 & 0.28 & 0.38 & 0.08 & 0.14 \\
\hline
\end{tabular}

$r=$ Pearson's correlation coefficient, $p=$ Significance, $R^{2}=$ coefficient of determination 
low and upper-middle-income countries for both overweight and obesity prevalence.

\section{Analysis of all countries}

The relationship between per capita fat supply and prevalence of both overweight and obesity for all the countries is noted to be logarithmic with strong correlations (Fig. 1a and b respectively). The overweight prevalence of all included countries showed a significant positive correlation $(r=0.64$, $p<0.001)$ and $41 \%$ of the data fit the regression model between per capita fat supply and overweight prevalence $\left(R^{2}=0.41\right)$ (Fig. 1a). The obesity prevalence of all included countries also showed a significant positive correlation $(r=0.59, p<0.001)$ with the per capita fat supply and $34 \%$ of the data fit the regression model between per capita fat supply and obesity prevalence $\left(R^{2}=0.34\right)$ (Fig. $\left.1 \mathrm{~b}\right)$. The regression lines obtained by the correlation analysis indicated an upward tendency, and, as indicated, nearly all included countries scattered around both lines, with only a few outliers (including Egypt and Kiribati). The lower end of these both lines was densely populated by most of the low-income and lower-middle-income countries, except for a few countries as outliers (including Kiribati, Egypt, Algeria, El Salvador, Bolivia). The upper ends of both lines were greatly populated by most of the high-income countries. All upper-middle-income countries (excluding China) scattered around the middle to the upper end of the regression line.

\section{Analysis based on GNI}

Scatter plots depicting the association between the above variables in each income group based on GNP were also generated (Fig. 2a-h). All of the regression lines produced by the correlation analysis similarly indicated a upward trend.

\section{Analysis of low-income countries}

Among the low-income countries, Haiti showed the highest prevalence of both overweight (54.9\%) and obesity (22.7\%) while Ethiopia showed the lowest prevalence of both overweight (20.9\%) and obesity (4.5\%). However, Gambia and Madagascar showed the highest (27.3\%) and lowest (10.5\%) per capita fat supply among the lowincome group respectively. Both overweight and obesity prevalence were not significantly correlated with per capita fat supply $(r=0.23, p=0.28$ and $r=0.29, p=0.17$ correspondingly) (Fig. 2a and 2b). However, the correlation effect significantly changed after removing the outliers (Yemen, Haiti) from the analysis, which then gave a significant correlation at both overweight $(r=0.49, p=0.02)$ and obesity $(r=0.67, p<0.001)$ prevalence with $24 \%$ and $45 \%$ of variations for overweight $\left(R^{2}=0.24\right)$ and obesity $\left(R^{2}=0.45\right)$ respectively (Supplementary Table 2$)$.

\section{Analysis of lower-middle-income countries}

The prevalence of overweight ranged from 19.7\% (India) to $78.8 \%$ (Kiribati), while obesity ranged from $3.6 \%$ (Bangladesh) to $46.0 \%$ (Kiribati). A wide range of per capita fat supply, representing 11.3\% Bangladesh and 30.3\% Kiribati was found in this group. It is noteworthy that

(See figure on next page.)

Fig. 1 a Correlation between per capita fat supply (as a percentage of total calorie supply) and the prevalence of overweight among all selected countries. Afghanistan-AFG; Albania-ALB; Algeria-DZA; Angola- AGO; Antigua and Barbuda-ATG; Argentina-ARG; Armenia-ARM; Australia- AUS; Austria-AUT; Azerbaijan-AZE; Bahamas- BHS; Bangladesh-BGD; Barbados-BRB; Belarus-BLR; Belgium-BEL; Belize-BLZ; Benin-BEN; Bolivia-BOL; Bosnia and Herzegovina-BIH; Botswana-BWA; Brazil-BRA; Bulgaria-BGR; Burkina Faso-BFA; Cape Verde-CPV; Cambodia-KHM; Cameroon-CMR; Canada-CAN; Central African Republic-CAF; Chad-TCD; China-CHN; Chile-CHL; Colombia-COL; Costa Rica- CRl; Cote d'Ivoire-CIV; Croatia-HRV; Cuba-CUB; Cyprus-CYP; Denmark-DNK; Djibouti-DJ;; Dominica-DMA; Dominican Republic-DOM; Ecuador-ECU; Egypt-EGY; El Salvador-SLV; Eswatini-SWZ; Ethiopia-ETH; Fiji-FJI; Finland-FIN; France-FRA; Gabon-GAB; Gambia- GMB; Georgia-GEO; Germany-DEU; Ghana-GHA; Greece-GRC; Grenada-GRD; Guatemala-GTM; Guinea-GIN; Guinea Bissau-GNB; Haiti-HTI; Honduras-HND; Hungary-HUN; India-IND; Iceland-ISL; Japan-JPN; Kenya-KEN; Kiribati-KIR; Lao People's Democratic Republic-LAO; Lesotho-LSO; Liberia-LBR; Madagascar-MDG; Malawi-MWl; Mali-MLI; Mauritania-MRT; Mauritius-MUS; Mozambique-MOZ; New Zealand-GBR; Niger-NER; North Korea-NER; Pakistan-PAK; Peru-RER; Rwanda-RWA; Republic of Korea-KOR; Sao Tome and Principe- STP; Sierra Leone-SLE; Sri Lanka-LKA; Sudan-SDN; Tajikistan-TJK; Togo-TGO; Uganda-UGA; United Kingdom-GBR; Yemen-YEM; Zimbabwe-ZWE. Low-income; : Lower-middle-income; :Upper-middle-income; X: High-income. b Correlation between per capita fat supply (as a percentage of total calorie supply) and the prevalence of obesity among all the countries. Afghanistan-AFG; Albania-ALB; Algeria-DZA; Angola- AGO; Antigua and Barbuda-ATG; Argentina-ARG; Armenia-ARM; Australia- AUS; Austria-AUT; Azerbaijan-AZE; Bahamas- BHS; Bangladesh-BGD; Barbados-BRB; Belarus-BLR; Belgium-BEL; Belize-BLZ; Benin-BEN; Bolivia-BOL; Bosnia and Herzegovina-BIH; Botswana-BWA; Brazil-BRA; Bulgaria-BGR; Burkina Faso-BFA; Cape Verde-CPV; Cambodia-KHM; Cameroon-CMR; Canada-CAN; Central African Republic-CAF; Chad-TCD; China-CHN; Chile-CHL; Colombia-COL; Costa Rica- CRI; Cote d'Ivoire-CIV; Croatia-HRV; Cuba-CUB; Cyprus-CYP; Denmark-DNK; Djibouti-DJl; Dominica-DMA; Dominican Republic-DOM; Ecuador-ECU; Egypt-EGY; El Salvador-SLV; Eswatini-SWZ; Ethiopia-ETH; Fiji-FJ; Finland-FIN; France-FRA; Gabon-GAB; Gambia- GMB; Georgia-GEO; Germany-DEU; Ghana-GHA; Greece-GRC; Grenada-GRD; Guatemala-GTM; Guinea-GIN; Guinea-Bissau-GNB; Haiti-HTI; Honduras-HND; Hungary-HUN; India-IND; Iceland-ISL; Japan-JPN; Kenya-KEN; Kiribati-KIR; Lao People's Democratic Republic-LAO; Lesotho-LSO; Liberia-LBR; Madagascar-MDG; Malawi-MWI; Mali-MLI; Mauritania-MRT; Mauritius-MUS; Mozambique-MOZ; New Zealand-GBR; Niger-NER; North Korea-NER; Pakistan-PAK; Peru-RER; Rwanda-RWA; Republic of Korea-KOR; Sao Tome and Principe- STP; Sierra Leone-SLE; Sri Lanka-LKA; Sudan-SDN; Tajikistan-TJK; Togo-TGO; Uganda-UGA; United Kingdom-GBR; Yemen-YEM; Zimbabwe- ZWE. Low-income; : Lower-middle-income; : Upper-middle-income; $X:$ High-income 

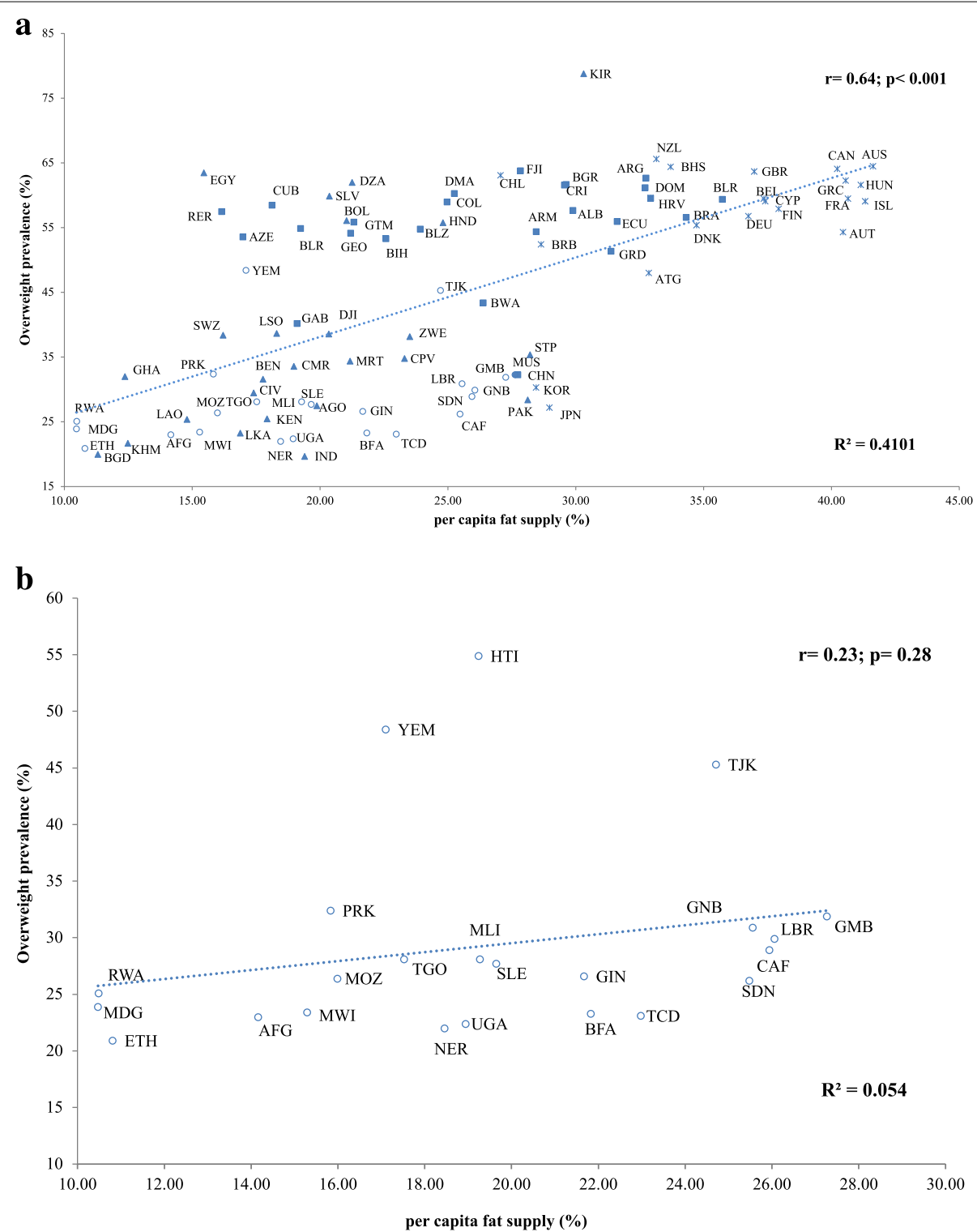

Fig. 1 (See legend on previous page.)

Kiribati had the highest prevalence of overweight and obesity, as well as the highest per capita fat supply. In this income category, both overweight and obesity prevalence were significantly correlated with per capita fat supply $(r=0.42, p=0.03$ and $r=0.42, p=0.03$ respectively) with the variation of $17 \%$ for overweight $\left(R^{2}=0.17\right)$ and $18 \%$ for obesity $\left(R^{2}=0.18\right)$ (Fig. $2 \mathrm{c}$ and d).

\section{Analysis of upper-middle-income countries}

Fiji had the highest prevalence of both overweight (30.2\%) and obesity $(63.8 \%)$, while China was the lowest country for those values (32.3\% and 6.2\% respectively). Per capita fat supply was ranged from $16.2 \%$ (Peru) to $35.7 \%$ (Belarus) among the upper-middle-income group. Countries in the upper-middle-income group did not show a significant correlation between per capita fat supply and prevalence of both overweight and obesity $(r=24, p=0.27$, and $r=0.28, p=0.08$ respectively) (Fig. $2 \mathrm{e}$ and 2f). However, after removing one outlier (China), a significant correlation was reported with obesity prevalence $(r=0.43$, $p=0.04)$ with $18 \%$ of the variation $\left(R^{2}=0.18\right)$ (Supplementary Table 2). All upper-middle-income countries except a couple of countries such as Georgia and China were clustered close to the regression line. 


\section{Analysis of high-income countries}

Among high-income countries, Japan showed the lowest prevalence for both overweight (27.2\%) and obesity (4.3\%). New Zealand presented the highest overweight prevalence $(65.6 \%)$ whereas the Bahamas showed the highest obesity prevalence (31.6\%). The per capita fat supply ranged from $27.1 \%$ (Chile) to $41.6 \%$ (Australia). Only overweight prevalence significantly correlated with per capita fat supply $(r=0.53, p=0.01)$ with $28 \%$ of the variation $\left(R^{2}=0.28\right)$ (Fig. $\left.2 \mathrm{~g}\right)$. However, per capita fat supply did not significantly correlate with the obesity prevalence $(r=0.38, p=0.08)$ in the high-income group (Fig. 2h). Almost all included countries in the regression line generated from the correlation analysis among the high-income group scattered around the line, with two countries, (Republic of Korea and Japan) as outliers.

\section{Discussion}

The results of our analysis have demonstrated that the per capita fat supply is a very good predictor for the prevalence of overweight and obesity at the country level. The link was found to be linear, with a substantial association between per capita fat supply and the incidence of both overweight and obesity. The correlation we have found in this study between fat intake and overweight and obesity is compatible with that demonstrated in epidemiological studies [28-30], and in clinical studies [31,32] which also shows the positive relationship between dietary fat consumption and increase of body-weight. Furthermore, in the pooled analysis, our findings on the link between fat consumption and the dependent variables of overweight and obesity demonstrate a substantial positive correlation.

However, the pattern of association of per capita fat supply to overweight and obesity differs according to income strata. According to that, a significant correlation between per capita fat supply and variables of both overweight and obesity was noted in the lower-middleincome group. At the same time, a significant correlation was also noted in high-income strata as well, but only for the overweight prevalence. Though the correlations were not significant in other sub-categories, that effect significantly changed for several sub-groups after removing few outliers. For example, the correlation coefficient was significantly noted for both variables of overweight and obesity in the low-income group after removing data from Yemen and Haiti, which were considered outliers. And, linear regression models between the per capita fat supply and prevalence of both overweight and obesity also increased after removing those two outliers. Moreover, correlation changed as significant for obesity in the upper-middle-income group after removing one outlier (China). The lack of significant correlation in the remaining two sub-categories (overweight

\footnotetext{
(See figure on next page.)

Fig. 2 a Correlation between per capita fat supply (as a percentage of total calorie supply) and the prevalence of overweight among low-income countries. Afghanistan-AFG; Burkina Faso-BFA; Central African Republic-CAF; Chad-TCD; Ethiopia- ETH; Gambia-GMB; Guinea-GIN; Guinea Bissau-GNB; Haiti-HTI; Liberia-LBR; Madagascar-MDG; Malawi-MWI; Mali-MLI; Mozambique-MOZ; Niger-NER; North Korea-NER; Rwanda-RWA; Sierra Leone-SLE; Sudan-SDN; Tajikistan-TJK; Togo-TGO; Uganda-UGA; Yemen-YEM. b Correlation between per capita fat supply (as a percentage of total calorie supply) and prevalence of obesity among low-income countries. Afghanistan-AFG; Burkina Faso-BFA; Central African Republic-CAF; Chad-TCD; Ethiopia- ETH; Gambia-GMB; Guinea-GIN; Guinea Bissau-GNB; Haiti-HTI; Liberia-LBR; Madagascar-MDG; Malawi-MWI; Mali-MLI; Mozambique-MOZ; Niger-NER; North Korea-NER; Rwanda-RWA; Sierra Leone-SLE; Sudan-SDN; Tajikistan-TJK; Togo-TGO; Uganda-UGA; Yemen-YEM. c Correlation between per capita fat supply (as a percentage of total calorie supply) and prevalence of overweight among lower-middle-income countries. Algeria-DZA; Angola-AGO; Bangladesh-BGD; Benin-BEN; Bolivia-BOL; Cambodia-KHM; Cameroon-CMR; Cape Verde-CPV; Cote d'Ivoire-CIV; Djibouti-DJI; Egypt-EGY; El Salvador-SLV; Eswatini-SWZ; Ghana-GHA; Honduras-HND; India-IND; Kenya-KEN; Kiribati-KIR; Lao People's Democratic Republic-LAO; Lesotho-LSO; Mauritania-MRT; Mauritius-MUS; Pakistan-PAK; Sao Tome and Principe-STP; Sri Lanka-LKA; Zimbabwe-ZWE. d Correlation between per capita fat supply (as a percentage of total calorie supply) and prevalence of obesity among lower-middle-income countries. Algeria-DZA; Angola-AGO; Bangladesh-BGD; Benin-BEN; Bolivia-BOL; Cambodia-KHM; Cameroon-CMR; Cape Verde-CPV; Cote d'Ivoire-CIV; Djibouti-DJl; Egypt-EGY; El Salvador- SLV; Eswatini-SWZ; Ghana-GHA; Honduras-HND; India-IND; Kenya-KEN; Kiribati-KIR; Lao People's Democratic Republic-LAO; Lesotho-LSO; Mauritania-MRT; Mauritius-MUS; Pakistan-PAK; Sao Tome and Principe-STP; Sri Lanka-LKA; Zimbabwe-ZWE. e Correlation between per capita fat supply (as a percentage of total calorie supply) and prevalence of overweight among upper-middle-income countries. Albania-ALB; Argentina-ARG; Armenia-ARM; Azerbaijan-AZE; Belarus-BLR; Belize-BLZ; Bosnia and Herzegovina-BIH; Botswana-BWA; Brazil-BRA; Bulgaria-BGR; China-CHN; Colombia-COL; Costa Rica-CRI; Cuba-CUB; Dominica-DM; Dominican Republic-DOM; Ecuador-ECU; Fiji- FJl; Gabon-GAB; Georgia-GEO; Grenada-GRD; Guatemala-GTM; Peru-RER. $\mathbf{f}$ Correlation between per capita fat supply (as a percentage of total calorie supply) and prevalence of obesity among upper-middle-income countries. Albania-ALB; Argentina-ARG; Armenia-ARM; Azerbaijan-AZE; Belarus-BLR; Belize- BLZ; Bosnia and Herzegovina- BIH; Botswana- BWA; Brazil- BRA; Bulgaria- BGR; China- CHN; Colombia- COL; Costa Rica- CRl; Cuba- CUB; Dominica- DM; Dominican Republic- DOM; Ecuador- ECU; Fiji- FJl; Gabon- GAB; Georgia- GEO; Grenada- GRD; Guatemala- GTM; Peru- RER. g Correlation between per capita fat supply (as a percentage of total calorie supply) and prevalence of overweight among high-income countries. Antigua and Barbuda- ATG; Australia- AUS; Austria- AUT; Bahamas- BHS; Barbados- BRB; Belgium- BEL; Canada- CAN; Chile- CHL; Croatia- HRV; Cyprus- CYP; Denmark- DNK; Finland- FIN; France- FRA; Germany- DEU; Greece- GRC; Hungary- HUN; Iceland- ISL; Japan- JPN; New Zealand- GBR; Republic of Korea- KOR; United Kingdom- GBR. $\mathbf{h}$ Correlation between per capita fat supply (as a percentage of total calorie supply) and prevalence of obesity among high-income countries. Antigua and Barbuda- ATG; Australia- AUS; Austria- AUT; Bahamas- BHS; Barbados- BRB; Belgium- BEL; Canada- CAN; Chile- CHL; Croatia- HRV; Cyprus- CYP; Denmark- DNK; Finland- FIN; France- FRA; Germany- DEU; Greece- GRC; Hungary- HUN; Iceland- ISL; Japan- JPN; New Zealand- GBR; Republic of Korea- KOR; United Kingdom- GBR
} 
a

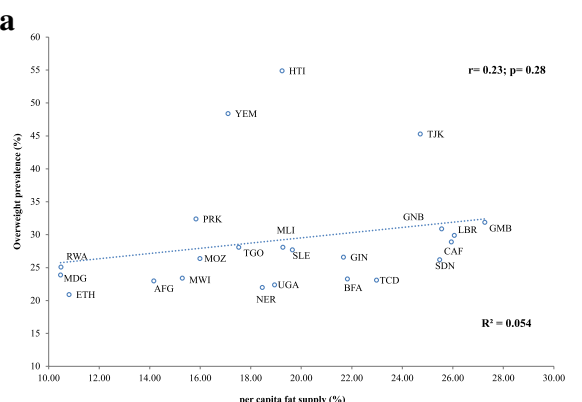

c

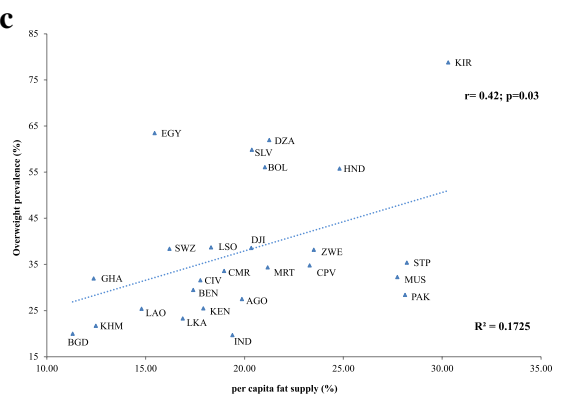

e

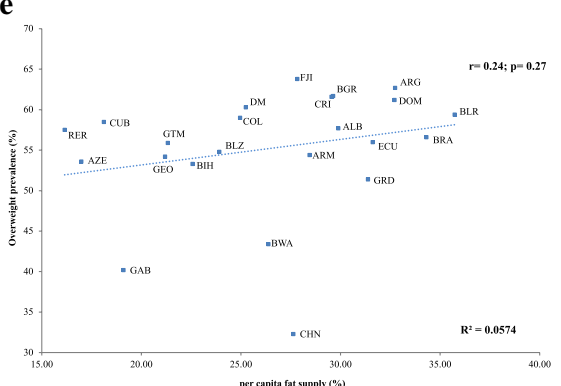

g

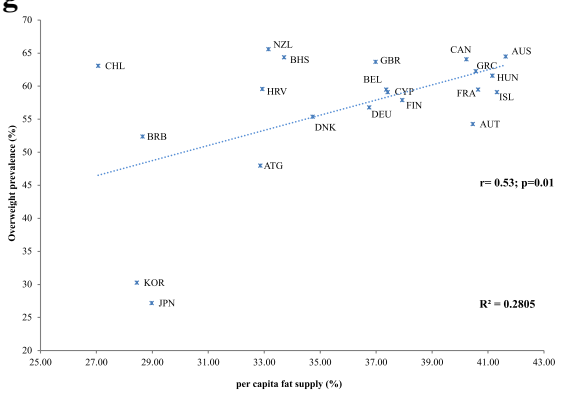

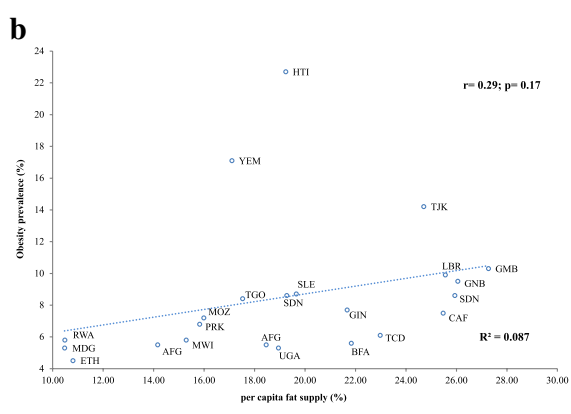

d
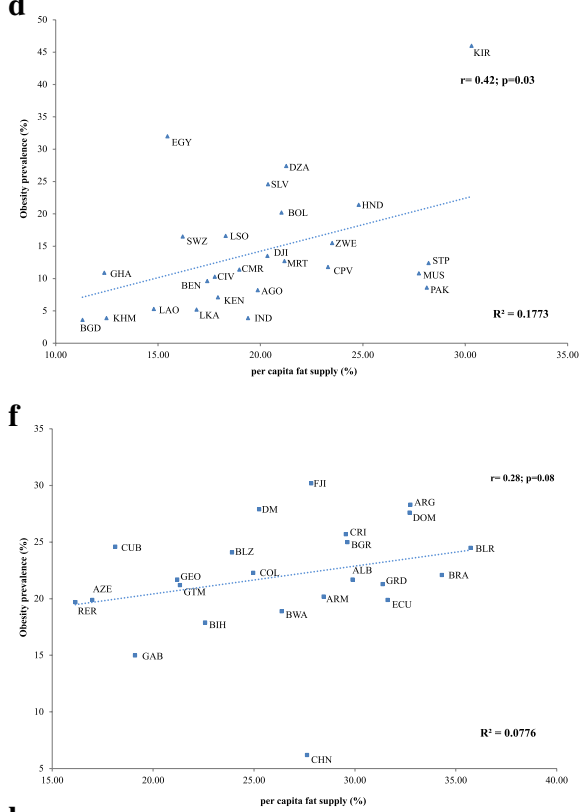

h

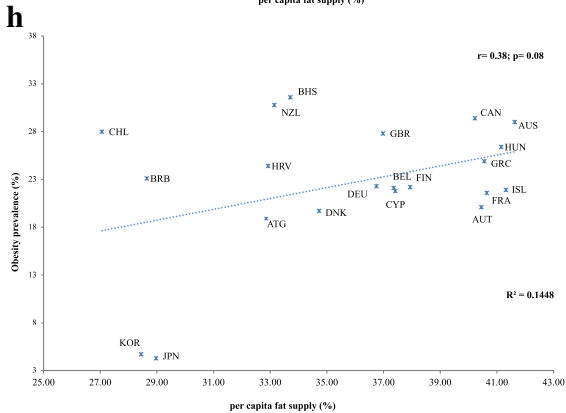

Fig. 2 (See legend on previous page.)

in upper-middle-income and obesity in high-income groups) may have been due to the insufficient data points, with a smaller number of countries.

The joint WHO/FAO consultation on fats and oils proposed that dietary fat should supply a minimum of $15 \%$ of TEI, but not exceed $30-35 \%$ of TEI for most adults [33]. The country-specific analysis of the current study has found a range of $10.5-41.6 \%$ of fat energy ratio between 2014-16. According to our analysis, seven countries fell below the minimum recommendation of $15 \%$ of dietary energy supply from fat, all of which were in the low-income (Ethiopia, Ghana, Cambodia, and Lao People's Democratic Republic) and lower-middle-income (Madagascar, Rwanda, and Afghanistan) categories. Thirteen countries exceeded the $35 \%$ maximum, with twelve countries being in the high-income group and one in the upper-middle-income group. It appears that the 
countries with an excess of per capita fat supply are generally economically developed countries.

When analyzing the factors that influence fat consumption patterns, assessments of fat consumption statistics suggest that persons in the lowest socioeconomic level in most developed countries take greater fatty foods [34]. Studies have shown that gender [35] and age [36] differences were also found in consumption of fatty foods. Moreover, urbanization is also strongly associated with the increasing consumption of fat in developing countries [37]. In addition to that, the physical environment, level of education, sociological, and individual factors also affect the altitude of fat consumption. Therefore, this entire phenomenon is part of an overall change in food habits and then determines the total quantity of fat availability at the country level.

Obesity caused by a high-fat diet is explained by a number of physiological processes. These include low satiating effects, as well as changes in hormones involved in energy balance [38]. More dietary fat leads to higher obesity because fat contains $9 \mathrm{kcal} / \mathrm{g}$ of energy compared to $4 \mathrm{kcal} / \mathrm{g}$ for carbs and protein [39]. It is evident that highfat meals have a high energy density, and so the overall fat content of the diet is an important determinant in energy balancing. Furthermore, weaker satiety signals from fats than from carbohydrate and protein have been proposed to involved in fat-rich diet overconsumption of calories [40]. The extra eating caused by fat-rich diets is due to their post-ingestion effect, which may increase food intake by conditioning sensory preference [41]. Furthermore, protein and carbohydrate stimulate significant auto-regulatory modifications in oxidation in response to variations in intake, but fat is at the bottom of an oxidative hierarchy that controls fuel choices [42].

Due to unavailability from relevant UN organizations, all information on the two variables we utilized in our research was not equally available for all nations throughout the world. As a result, the number of countries used in this analysis was limited to those possessing relevant data. FAO, WHO, and the World Bank are international institutions that provide specialist information in their respective areas. Before they were released, they analyzed these data in terms of their potential uses, such as scientific research and decision making. This indicates that while mistakes have been decreased, certain inaccuracies relating to reporting quality may still exist in the data.

\section{Limitations}

It must be noted that there are several limitations to this study. Firstly, there may be some possible confounding variables (e.g., prevalence of physical inactivity, absolute total calories, and fat consumption or food wastage) that were not included in our study and may have influenced the association we discovered. However, it is impossible to determine what such factors may be in the current investigation. Second, we could only utilize an international food database that measures per capita calorie and fat supply, not actual human consumption. However, there are no direct assessments of actual human intake that can account for food waste and give exact statistics of food consumption globally. Third, because the data studied are computed per capita in each country, we could only find the correlation at the country level, which does not always equate to the same associations at the individual level. Fourth, BMI values of $25 \mathrm{~kg} / \mathrm{m} 2^{2}$ and $30 \mathrm{~kg} / \mathrm{m}^{2}$ were used as the cut-off points for classifying overweight and obesity in this study cohort. However, different cut-off points can be employed to define overweight and obesity among different ethnic groups. We used WHO country reports for this study to possibly reduce substantial discrepancies between countries, although more recently published data on the prevalence of overweight and obesity are available for some countries. Finally, the findings cannot be extended to the individual level because this is an ecological study.

\section{Future perspectives}

Prospective cohort studies and intervention studies are recommended in each country to investigate this link further. Furthermore, assessing heterogeneity in various amounts of animal fat and plant fat is important for determining a true depiction of the connection at the national level. Country-specific nutrition education messages that warn consumers about the consequences of a high-fat diet and how to restrict sources of fat consumption to maintain a healthy body weight are critical. Relevant authorities in the countries should implement food regulations, active initiatives to raise awareness of the consequences of high fat consumption and its sources, and related taxes on food industry based on the amount of fat used as an ingredient so that the public would make rational decisions.

\section{Conclusion}

In all nations, significant positive associations were found between the prevalence of overweight and obesity and country-specific per capita fat supply. The regression lines derived by the correlation analysis indicated an increasing trend. Most low-income and lower-middleincome nations were densely populated at the lower ends of both lines, indicating a low incidence of both overweight and obesity and a per capita low-fat supply. In contrast, most high-income nations filled the higher ends of both lines, showing a high incidence of both overweight and obesity with a per capita high fat supply. 


\section{Abbreviations}

BMI: Body Mass Index; CVD: Cardiovascular Disease; FAO: Food and Agricultural Organization; FBS: Food Balance Sheet; GHO: Global Health Observatory; GNI: Gross National Income; MUFA: Monounsaturated Fatty Acid; PUFA: Polyunsaturated Fatty Acid; SFA: Saturated Fatty Acid; TEl: Total energy intake; TG: Triglyceride; UN: United Nations; WHO: World Health Organization.

\section{Supplementary Information}

The online version contains supplementary material available at https://doi. org/10.1186/s40795-021-00496-2.

Additional file 1. Detailed information on the country-level prevalence of overweight and obesity and per capita fat supply and total calories

Additional file 2. Correlation coefficient and coefficient of determination between per capita fat supply and dependent variables-overweight and obesity in two income groups after removing outliers

\section{Acknowledgements}

None

\section{Authors' contributions}

PR and HS made a substantial contribution to design the conception. HS reviewed the literature and obtained the data. PR checked for accuracy of data. HS and PR were involved in retrieving data. HS involved in statistical analysis and drafting the manuscript. PR, RJ, and MC critically revised the manuscript. All authors read and approved the final manuscript.

\section{Funding}

None.

\section{Availability of data and materials}

All data for this study are publicly available and are ready for the public to download at no cost from the official websites of the World Bank [22], the WHO [20], and FAO [21]. Usage of these data for this research falls within the UN agency's public permission in their terms and conditions. There is no need to have formal permission to use the data for this study as public access to the databases is open. The sources and data robustness has been described in the section of "Methods". Furthermore, detailed information on the country-level prevalence of overweight and obesity and per capita fat supply and total calories are contained within Supplementary Table 1.

\section{Declarations}

\section{Ethics approval and consent to participate}

All data supporting our findings in this paper were freely downloaded from the United Nations (UN) agencies' websites. No ethical approval or written informed consent for participation was required.

\section{Consent for publication}

Not applicable.

\section{Competing interests}

The authors declare no conflict of interest.

\section{Author details}

${ }^{1}$ Health and Wellness Unit, Faculty of Medicine, University of Colombo, Colombo, Sri Lanka. ${ }^{2}$ Department of Physiology, Faculty of Medicine, University of Colombo, Colombo, Sri Lanka. ${ }^{3}$ Institute of Health and Biomedical Innovation, Queensland University of Technology, Brisbane, QLD, Australia. ${ }^{4}$ Laboratory of Hygiene, Social \& Preventive Medicine and Medical Statistics, School of Medicine, Faculty of Health Sciences, Aristotle University of Thessaloniki, University Campus, 54124 Thessaloniki, Greece. ${ }^{5}$ Department of Pharmacology, Faculty of Medicine, University of Colombo, Colombo, Sri Lanka.

Received: 21 January 2021 Accepted: 28 December 2021

Published online: 13 January 2022

\section{References}

1. WHO fact sheet. Obesity and overweight. WHO. Published 2020. https:// www.who.int/news-room/fact-sheets/detail/obesity-and-overweight. Accessed 11 Oct 2020.

2. Ng M, Fleming T, Robinson M, et al. Global, regional, and national prevalence of overweight and obesity in children and adults during 1980-2013: A systematic analysis for the Global Burden of Disease Study 2013. The Lancet. 2014;384(9945):766-81. https://doi.org/10.1016/S01406736(14)60460-8.

3. $\mathrm{WHO} \mid$ Controlling the global obesity epidemic. WHO. Published online 2013. https://www.who.int/nutrition/topics/obesity/en/. Accessed 12 Oct 2020.

4. Lakerveld J, Mackenbach J. The Upstream Determinants of Adult Obesity. Obes Facts. 2017;10(3):216. https://doi.org/10.1159/000471489.

5. Bandurek I, Almond E, Brown S, et al. Diet and physical activity as determinants of weight gain, overweight and obesity: The WCRF/AICR evidence and policy implications. Proceedings of the Nutrition Society. 2020;79(OCE2). doi:https://doi.org/10.1017/S0029665120001561

6. Hill JO, Wyatt HR, Peters JC. Energy balance and obesity. Circulation. 2012;126(1):126-32. https://doi.org/10.1161/CIRCULATIONAHA.111. 087213.

7. Hill JO, Hill ME, Wyatt H. Dietary fat intake and regulation of energy balance: implications for obesity. J Nutr. 2000;130:284S-288S. https:// pubmed.ncbi.nlm.nih.gov/10721889/. Accessed 10 Dec 2020.

8. Roberts CK, Berger JJ, Barnard RJ. Long-term effects of diet on leptin, energy intake, and activity in a model of diet-induced obesity. J Appl Physiol. 2002;93(3):887-93. https://doi.org/10.1152/japplphysiol.00224. 2002.

9. Wilding J. Are the causes of obesity primarily environmental? Yes BMJ. 2012;345(7875):e5843. https://doi.org/10.1136/BMJ.E5843.

10. Suara SB, Siassi F, Saaka M, Foroshani AR, Asadi S, Sotoudeh G. Dietary fat quantity and quality in relation to general and abdominal obesity in women: a cross-sectional study from Ghana. Lipids in Health and Disease. 2020;19(1):1-13. https://doi.org/10.1186/S12944-020-01227-5.

11. Strychar I, Cohn JS, Renier G, et al. Effects of a Diet Higher in Carbohydrate/Lower in Fat Versus Lower in Carbohydrate/Higher in Monounsaturated Fat on Postmeal Triglyceride Concentrations and Other Cardiovascular Risk Factors in Type 1 Diabetes. Diabetes Care. 2009;32(9):1597-9. https://doi.org/10.2337/DC08-2322.

12. Pierce JP, Natarajan L, Caan BJ, et al. Influence of a diet very high in vegetables, fruit, and fiber and low in fat on prognosis following treatment for breast cancer: the Women's Healthy Eating and Living (WHEL) randomized trial. JAMA. 2007;298(3):289-98. https://doi.org/10.1001/ JAMA.298.3.289.

13. Kearney J. Food consumption trends and drivers. Philosophical Transactions of the Royal Society B: Biological Sciences. 2010;365(1554):2793807. https://doi.org/10.1098/rstb.2010.0149.

14. Kearney J. Food consumption trends and drivers. Philosophical Transactions of the Royal Society B: Biological Sciences. 2010;365(1554):2793. https://doi.org/10.1098/RSTB.2010.0149.

15. FAO, IFAD, UNICEF, WFP and WHO. In Brief to The State of Food Security and Nutrition in the World 2020. Transforming food systems for affordable healthy diets. Rome: FAO; 2020. https://doi.org/10.4060/ca9699en.

16. Brehm BJ, Seeley RJ, Daniels SR, D'Alessio DA. A Randomized Trial Comparing a Very Low Carbohydrate Diet and a Calorie-Restricted Low Fat Diet on Body Weight and Cardiovascular Risk Factors in Healthy Women. J Clin Endocrinol Metab. 2003;88(4):1617-23. https://doi.org/10.1210/jc. 2002-021480.

17. Johnston CS, Tjonn SL, Swan PD. High-Protein, Low-Fat Diets Are Effective for Weight Loss and Favorably Alter Biomarkers in Healthy Adults. In: Journal of Nutrition. 2004;134:586-91. https://doi.org/10.1093/jn/134.3. 586 American Institute of Nutrition.

18. Sylvetsky AC, Edelstein SL, Walford G, et al. A High-Carbohydrate, HighFiber, Low-Fat Diet Results in Weight Loss among Adults at High Risk of Type 2 Diabetes. The Journal of Nutrition. 2017;147(11):jn252395. https:// doi.org/10.3945/jn.117.252395.

19. Micha R, Khatibzadeh S, Shi P, et al. Global, regional, and national consumption levels of dietary fats and oils in 1990 and 2010: a systematic analysis including 266 country-specific nutrition surveys. BMJ. 2014;348. doi:https://doi.org/10.1136/BMJ.G2272 
20. WHO. Global Health Observatory, the data repository. WHO. Published 2016. https://www.who.int/data/gho. Accessed 2 Oct 2020.

21. FAO. FAOSTAT-Food Balance Sheet. FAO. Published 2020. http://www.fao. org/faostat/en/\#home. Accessed 2 Oct 2020.

22. World Bank Country and Lending Groups - World Bank Data. Accessed October 30, 2020. https://datahelpdesk.worldbank.org/knowledgebase/ articles/906519

23. Energy and protein requirements. http://www.fao.org/3/AA040E/AA040 E00.htm. Accessed 2 Oct 2020

24. Davis B, Wansink B. Fifty years of fat: News coverage of trends that predate obesity prevalence Health behavior, health promotion and society. BMC Public Health. 2015;15(1):629. https://doi.org/10.1186/ s12889-015-1981-1.

25. What is the World Bank Atlas method? - World Bank Data Help Desk. https://datahelpdesk.worldbank.org/knowledgebase/articles/77933what-is-the-world-bank-atlas-method. Accessed 30 Oct 2020

26. New country classifications by income level: 2019-2020. https://blogs. worldbank.org/opendata/new-country-classifications-income-level2019-2020. Accessed 30 Oct 2020.

27. International Organization for Standardization. In The International Standard for country codes and codes for their subdivisions. https://www.iso. org/obp/ui/\#search. Accessed 19 Nov 2020.

28. Suara SB, Siassi F, Saaka M, Foroshani AR, Asadi S, Sotoudeh G. Dietary fat quantity and quality in relation to general and abdominal obesity in women: A cross-sectional study from Ghana. Lipids Health Dis. 2020;19(1):67. https://doi.org/10.1186/s12944-020-01227-5.

29. Melanson EL, Astrup A, Donahoo WT. The Relationship between Dietary Fat and Fatty Acid Intake and Body Weight, Diabetes, and the Metabolic Syndrome. Ann Nutr Metab. 2009;55:229-43. https://doi.org/10.1159/ 000229004.

30. Raatz SK, Conrad Z, Johnson LAK, Picklo MJ, Jahns L. Relationship of the reported intakes of fat and fatty acids to body weight in US adults. Nutrients. 2017:9(5):438. https://doi.org/10.3390/nu9050438.

31. Kuller LH, Simkin-Silverman LR, Wing RR, Meilahn EN, Ives DG. Women's Healthy Lifestyle Project: A randomized clinical trial: results at 54 months. Circulation. 2001;103(1):32-7. https://doi.org/10.1161/01.CIR.103.1.32.

32. Howard BV, Manson JE, Stefanick ML, et al. Low-Fat Dietary Pattern and Weight Change Over 7 Years: The Women's Health Initiative Dietary Modification Trial. JAMA. 2006;295(1):39-49. https://doi.org/10.1001/JAMA. 295.1.39.

33. Joint WHO/FAO Expert Consultation. DIET, NUTRITION AND THE PREVENTION OF CHRONIC DISEASES.; 2003. https://apps.who.int/iris/bitstream/ handle/10665/42665/WHO_TRS_916.pdf?sequence=1. Accessed $22 \mathrm{Nov}$ 2020

34. Dinsa GD, Goryakin Y, Fumagalli E, Suhrcke M. Obesity and socioeconomic status in developing countries: A systematic review. Obes Rev. 2012;13(11):1067-79. https://doi.org/10.1111/j.1467-789X.2012.01017.x.

35. Bennett E, Peters SAE, Woodward M. Sex differences in macronutrient intake and adherence to dietary recommendations: Findings from the UK Biobank. BMJ Open. 2018;8(4):e020017. https://doi.org/10.1136/bmjop en-2017-020017.

36. Inelmen EM, Toffanello ED, Enzi G, et al. Differences in dietary patterns between older and younger obese and overweight outpatients. The journal of nutrition, health \& aging. 2008;12(1):3-8. https://doi.org/10. 1007/BF02982157.

37. Seto KC, Ramankutty N. Hidden linkages between urbanization and food systems. Science. 2016;352(6288):943-5. https://doi.org/10.1126/science. aaf7439.

38. Hariri N, Thibault L. High-fat diet-induced obesity in animal models. Nutr Res Rev. 2010;23(2):270-99. https://doi.org/10.1017/S0954422410000168.

39. Rolls BJ. The role of energy density in the overconsumption of fat. In: Journal of Nutrition. 2000;130:268S-271S. https://doi.org/10.1093/jn/ 130.2.268s American Institute of Nutrition.

40. Brennan IM, Luscombe-Marsh ND, Seimon RV, et al. Effects of fat, protein, and carbohydrate and protein load on appetite, plasma cholecystokinin, peptide YY, and ghrelin, and energy intake in lean and obese men. Am J Physiol Gastrointest Liver Physiol. 2012;303(1):129-40. https://doi.org/10. 1152/ajpgi004782011.
41. Sclafani A, Ackroff K. Role of gut nutrient sensing in stimulating appetite and conditioning food preferences. American Journal of Physiology Regulatory, Integrative and Comparative Physiology. 2012;302(10):R1119. https://doi.org/10.1152/AJPREGU.00038.2012.

42. Galgani J, Ravussin E. Energy metabolism, fuel selection and body weight regulation. Int J Obes. 2008;32(SUPPL. 7):S109. https://doi.org/10.1038/ijo. 2008.246 .

\section{Publisher's Note}

Springer Nature remains neutral with regard to jurisdictional claims in published maps and institutional affiliations.

Ready to submit your research? Choose BMC and benefit from

- fast, convenient online submission

- thorough peer review by experienced researchers in your field

- rapid publication on acceptance

- support for research data, including large and complex data types

- gold Open Access which fosters wider collaboration and increased citations

- maximum visibility for your research: over 100M website views per year

At BMC, research is always in progress.

Learn more biomedcentral.com/submissions 